\title{
PENGEMBANGAN PENILAIAN PEMBELAJARANAKUNTANSI KONTEKSTUAL BERBASIS LESSON STUDY DI SMA
}

\author{
Suyatmini, Sutama, Wafrotur Rohmah, Titik Asmawati \\ Pendidikan Akuntansi, Universitas Muhammadiyah Surakarta \\ e-mail: suy276@ums.ac.id
}

\begin{abstract}
This study aims to (1) analyze and describe the assessment of accounting learning conducted by high school teachers in Surakarta City-Central Java. (2) the development of lesson study based contextual accounting learning assessment. This study uses the research and development approach. Research subjects of high school accounting teachers in Surakarta City. Methods of data collection, interviews, observation and documentation. Data analysis techniques use interactive analysis which includes data collection, data reduction, data display and verification. The validity of the data uses triangulation methods and sources. The results of the study indicate that the judgments carried out include affective assessment, cognitive assessment and psychomotor assessment. The evaluation of accounting learning in high school of Surakarta City for affective aspects are using two ways, namely the assessment of spiritual attitudes competency and social attitudes assessment. Assessment of spiritual attitudes uses selfassessment techniques. Social attitude competency assessment uses observation techniques, self-assessment journals, and peers. Assessment of accounting learning for cognitive aspects using tests and assignments. There are three learning assessments for psychomotor aspects, namely project appraisal, performance, and portfolio. Development is carried out on assessment instruments for both affective, cognitive, and psychomotor aspects. The development of the affective aspect is carried out by the spiritual attitude competency assessment instrument and the social attitude competency assessment instrument with observation techniques. The development of cognitive aspects is carried out on the instrument for assessing cognitive aspects and the timing of the implementation of cognitive instruments. Development of psychomotor aspects is carried out on the implementation of psychomotor instruments.
\end{abstract}

Keywords: Assessment, learning, accounting, contextual, lesson study. 


\section{PENDAHULUAN}

Pembelajaran merupakan proses hubungan timbal balik antara guru dan siswa beserta unsur-unsur yang ada didalamnya. Pembelajaran bagian dari pendidikan yang didalamnya ditunjang unsur pembelajaran antara lain tujuan, materi pelajaran, sarana dan prasarana, situasi atau kondisi belajar, media pembelajaran, lingkungan belajar, metode pembelajaran dan evaluasi.

Pelajaran akuntansi cenderung dipandang sebagai mata pelajaran yang "kurang diminati" atau "kalau bisa dihindari" oleh sebagian siswa dan kurangnya kesabaran bahwa akun-akun yang ada dalam akuntansi mengajarkan untuk dapat berpikir rasional, cermat, efisien dan efektif. Oleh karena itu kretivitas seorang guru dalam mengajar akuntansi menjadi faktor penting agar akuntansi menjadi mata pelajaran yang menyenangkan dan menarik di dalam kelas. Hamalik (2008: 11) menyatakan bahwa guru yang baik tidak saja menguasai spesialisasi ilmunya, akan tetapi harus mengenal proses belajar manusia, cara-cara mengajar, penggunaan alat-alat peraga, teknik penilaian dan sebagainya. Guru sebagian besar belum memahami standar isi, kurang mampu dalam mengembangkan silabus dan materi pokok, serta guru kesulitan dalam merumuskan indikator. Guru dalam mengajar masih berorientasi kepada buku, abstrak, dan masih sedikit guru yang menghubungkan materi ajar dengan kehidupan sehari-hari siswa. Guru tidak mengetahui kondisi awal siswa sehingga guru kurang bisa memotivasi siswa untuk belajar (Sutama, 2011: 28-32). Seharusnya dalam proses pembelajaran guru dapat memanfaatkan lingkungan sebagai basis pembelajaran, karena dapat membantu guru dan siswa dalam mencapai tujuan pembelajaran (Sarjono \& Suyatmini, 2014: 12). Hal senada juga dilakukan oleh LSM Sari dalam melakukan proses pembelajaran (Sarjono \& Suyatmini: 2013: 102). Dalam proses pembelajaran berbasis lingkungan juga dapat merangsang mahasiswa untuk mandiri. Demikian pula dalam problem based learning, hasil penelitian menunjukkan suasana kelas menjadi lebih aktif-kreatif, dan mampu meningkatkan sikap mandiri mahasiswa (Wafroturrohmah \& Suyatmini, 2008: 162).

Berdasarkan pemikiran di atas dan dalam kondisi yang mendesak, seyogyanya guru memfokuskan pada pengelolaan pembelajaran dengan strategi sesuai kebutuhan, yaitu mengembangkan pembelajaran akuntansi kontekstual berbasis lesson study. Johnson (2009: 15) menyatakan bahwa pembelajaran kontekstual dapat merangsang wawasan anak dalam rangka merespon lingkungan. Lesson study merupakan model pembinaan profesi pendidik melalui pengkajian pembelajaran secara kolaboratif dan berkelanjutan berlandaskan prinsip-prinsip kolegialitas mutual learning untuk membangun komunitas belajar (Susilo, dkk., 2009: vi). Hal ini sesuai dengan prinsip pelaksanaan kurikulum 2013, yakni siswa harus mendapatkan pelayanan pendidikan yang bermutu, serta memperoleh kesempatan untuk mengekspresikan dirinya secara bebas, dinamis, dan menyenangkan.

Cockroft (1982) menyatakan bahwa siswa perlu belajar akuntansi dengan alasan, akuntansi merupakan alat komunikasi yang sangat kuat, teliti, dan tidak membingungkan. Namun, pendekatan pembelajaran akuntansi di Sekolah Menengah Atas (SMA) di Surakarta sebagian besar masih berpusat pada guru. Hal ini disebut sebagai aktivitas mengajar, bukan merupakan aktivitas belajar. 
Dominasi guru dalam mengajar dapat berakibat komunikasi belajar akuntansi tidak efektif.

Demikian juga berdasarkan hasil observasi pendahuluan dalam pembelajaran akuntansi di SMA Kota Surakarta masih ditemukan kesenjangan dalam pelaksanaan penilaian pada aspek ketrampilan dan kemampuan. Hal ini didukung dari hasil analisis RPP Akuntansi di SMA Kota Surakarta ditemukan adanya kesenjangan penilaian kompetensi psikomotorik dan kognitif. Kesenjangan pada penilaian ketrampilan, yaitu setiap materi ajar dinilai dalam setiap tatap muka. Kesenjangan penilaian kemampuan, yaitu pada kurangnya variasi soal. Berdasarkan observasi awal menunjukkan bahwa sebagian besar guru masih kesulitan didalam mengatur waktu pada merencanakan penilaian sikap, pengetahuan dan ketrampilan, kesulitan dalam penyusunan instrumen penilaian dan kesulitan dalam pelaksanaan penilaian, terlalu rumit serta perlu waktu yang lama untuk menyusun laporannya. Menurut Kunandar (2013: 55) Penilaian pembelajaran merupakan proses pengumpulan data yang dapat memberikan gambaran perkembangan belajar.

Penilaian pembelajaran merupakan hal yang tidak bisa dipisahkan dari proses pembelajaran dan merupakan sesuatu yang sangat penting. Dikarenakan penilaian memberikan gambaran perkembangan belajar peserta didik selama mengikuti pembelajaran. Gambaran perkembangan peserta didik perlu diketahui oleh guru agar dapat memastikan bahwa peserta didik mengalami proses pembelajaran dengan benar. Tujuan penelitian ini untuk menganalisis dan mendiskripsikan penilaian pembelajaran Akuntansi yang dilakukan guru-guru akuntansi di SMA kota surakarta dan untuk mengembangakan penilaian pembelajaran akuntansi berbasis lesson study.

\section{METODE PENELITIAN}

Penelitian ini secara keseluruhan menggunakan penelitian dan pengembangan (Research and Development). Penelitian dan pengembangan adalah suatu proses untuk mengembangkan produk yang telah ada dan dapat dipertanggung jawabkan (Sutama, 2012: 183; Gall, Gall, \& Borg, 2003). Lokasi penelitian Sekolah Menengah Atas di Kota Surakarta, Jawa Tengah. Subyek penelitian guru-guru Akuntansi SMA di Kota Surakarta. Metode pengumpulan data, wawancara observasi dan dokumentasi. Teknik analisis data menggunakan analisis interaktif yang meliputi pengumpulan data, reduksi data, data display dan verifikasi. Keabsahan data menggunakan triangulasi metode dan sumber.

\section{HASIL PENELITIAN DAN PEMBAHASAN}

Pada silabus telah diberikan rujukan mengenai jenis penilaian yang akan digunakan untuk setiap pembelajarannya. Penilaian pencapaian KD oleh siswa dilakukan dengan didasarkan kepada indikator yang telah dikembangkan sebelumnya. Penilaian dilakukan dengan menggunakan tes dan nontes dalam bentuk tertulis (paper and pencil test) maupun lisan, pengamatan kinerja, pengukuran sikap, penilaian hasil karya berupa tugas, proyek dan/atau produk, penggunaan portofolio, dan penilaian diri (self asessment). Oleh karena pada setiap pembelajaran siswa dituntut agar menghasilkan karya, maka penyajian portofolio adalah cara penilaian yang wajib dilakukan pada jenjang pendidikan dasar dan 
menengah. Penilaian merupakan serangkaian kegiatan untuk memperoleh, menganalisis, dan menafsirkan data tentang proses dan hasil belajar siswa yang dilakukan secara sistematis dan berkesinambungan, sehingga menjadi informasi yang bermakna dalam pengambilan keputusan. Untuk merancang sebuah penilaian yang baik maka guru, sebaiknya memperhatikan hal-hal berikut: (a) Penilaian diarahkan untuk mengukur pencapaian kompetensi dasar, (b) Penilaian menggunakan acuan kriteria; yaitu berdasarkan apa yang bisa dilakukan peserta didik setelah mengikuti proses pembelajaran, dan bukan untuk menentukan posisi seseorang terhadap kelompoknya (c) Sistem yang direncanakan adalah sistem penilaian yang berkelanjutan. Berkelanjutan dalam arti semua indikator ditagih, kemudian hasilnya dianalisis untuk menentukan KD yang telah dimiliki dan yang belum, serta untuk mengetahui kesulitan siswa (d) Hasil penilaian dianalisis untuk menentukan tindak lanjut. Tindak lanjut berupa perbaikan proses pembelajaran berikutnya, program remedi bagi peserta didik yang pencapaian kompetensinya di bawah ketuntasan, dan program pengayaan bagi siswa yang telah memenuhi ketuntasan. (e) Sistem penilaian harus disesuaikan dengan pengalaman belajar yang ditempuh dalam proses pembelajaran. Misalnya, jika pembelajaran menggunakan pendekatan tugas observasi lapangan maka evaluasi harus diberikan baik pada proses misalnya teknik wawancara, maupun produk berupa hasil melakukan observasi lapangan.

Penilaian dalam pembelajaran akuntansi di SMA Kota Surakarta meliputi penilaian afektif, psikomotorik dan kognitif yang ketiganya merupakan hal yang berkesinambungan antara sikap, keterampilan dan akademik yang harus dimiliki siswa. Aspek yang dinilai dalam evaluasi diantaranya spiritualnya yang merupakan ketaqwaan pada Allah SWT. Untuk penilaian dibidang psikomotorik atau penilaian ketrampilan, guru dapat mengamati dan memberikan suatu kinerja yang membuat cara berpikir cepat dalam menyelesaikan tugas yang diberikan guru, proses dalam penilaian ini dapat berupa tugas portofolio dan dilaksanakan saat materi pembelajaran akuntansi berlangsung dalam kelas. Sedangkan penilaian kognitif berupa tes tertulis, lisan, atau penugasan yang dilaksanakan pada saat ulangan harian, ujian tengah semester, dan akhir semester. Hasil dari evaluasi, dapat berupa hasil akhir saat ujian akhir semester dalam bentuk raport, dan siswa dapat mengetahui nilai akuntansi tersebut dan guru mengetahui kemampuan siswa. Sebelum guru melakukan evaluasi hasil belajar adalah melakukan telaah terhadap kurikulum. Telaah kurikulum ini dimaksudkan untuk mencermati tipe hasil belajar yang termuat di dalam rumusan kompetensi dasar dan indikator. Dengan mengenali tipe hasil belajar tersebut, guru akan memilih dalam menentukan teknik dan instrumen evaluasi secara tepat. Misalnya, rumusan kompetensi dan indikatornya memuat tipe hasil belajar kognitif tingkatan pemahaman, maka teknik evaluasi yang dapat digunakan adalah tes bentuk obyektif model pilihan ganda atau dengan tes bentuk uraian. Jika tipe hasil hasil belajarnya adalah psikomotor, maka teknik evaluasi yang cocok adalah dengan menggunakan tes kinerja dan instrumennya berupa skala penilaian. Sukiman (2012: 40). Penilaian yang tepat bagi pendidikan memberikan hasil yang sesuai harapan, karena penilaian pendidikan adalah proses pengumpulan dan pengolahan informasi untuk menentukan pencapaian hasil belajar siswa Hamdani (2011: 301). 
Penilaian dalam pendidikan sangatlah penting, karena untuk mengetahui kemampuan siswa dalam pembelajaran akuntansi. Selain penilaian secara afektif, psikomotorik dan kognitif, penilaian yang dilakukan oleh guru pada siswa berupa tes secara formatif yang ditujukan untuk memperbaiki proses belajar mengajar, yang dilakukan pada setiap akhir pembahasan suatu pokok bahasan sedangkan tes secara sumatif yang ditujukan untuk keperluan penentuan angka kemajuan atau hasil belajar siswa. penilaian pada dasarnya adalah untuk mengetahui hasil akhir dalam suatu pembelajaran berlangsung yang mencakup pengetahuan, keterampilan, sikap dan nilai-nilai yang diwujudkan dalam kebiasaan berpikir dan bertindak. Hal itu akan membuat siswa bersemangat dalam belajar akuntansi untuk mencapai hasil dengan baik dalam memahami akuntansi.

Penilaian dalam pembelajaran akuntansi sangat bervariasi sehingga tidak membosankan, seperti halnya penilaian dalam bentuk penugasan dan bentuk kelompok, itulah yang membuat siswa harus lebih giat dan memahami akuntansi. Penilaian pembelajaran yang terpadu, merupakan penilaian pencapaian kompetensi dasar peserta didik dilakukan berdasarkan indikator. Penilaian digunakan menggunakan tes dan nontes dalam bentuk tertulis maupun lisan, pengamatan kinerja, pengukuran sikap, penilaian hasil karya berupa tugas, proyek dan atau produk, penggunaan portofolio dan penilaian diri Trianto (2010: 123). Dari segi pentahapan, evaluasi baik dilakukan baik pada tahap perencanaan maupun pada tahap pelaksanaan. Sedangkan dari segi sasaran, penilaian difokuskan pada proses maupun produk pembelajaran.

Penilaian bertujuan untuk mengetahui daya serap siswa dalam pembelajaran akuntansi terhadap materi yang diberikan guru dalam bentuk soal-soal untuk mengetahui kemampuan siswa. Penilaian dengan memberikan soal yang tepat akan menghasilkan alat ukur yan efektif dan efisien yang mampu memberikan hasil yang diharapkan sesuai KKM dan meningkatkan kualitas pembelajaran akuntansi. Penilaian pembelajaran akuntansi juga bervariasi. Evaluasi dilakukan secara kelompok dan individu, penilaian kelompok didasarkan nilai kelompok tersebut. Sedangkan evaluasi individu didasarkan pada hasil individu baik secara lisan maupun secara tertulis atau penugasan.

Kurikulum telah tumbuh sebagai faktor penting dalam mempersiapkan siswa akuntansi untuk masa depan kerja. Dalam kerangka konseptual terbukti untuk menawarkan beberapa manfaat potensial untuk evaluasi desain kurikulum dan penelitian masa depan dapat memberikan pengujian yang lebih ketat dari kerangka kerja pada berbagai tahap pembangunan. Dilihat dari kualitas juga telah menunjukkan potensi yang di gunakan dalam menentukan relevansi kurikulum pada tingkat topik pada setiap minggu dan mungkin merupakan pendekatan yang peneliti lakukan juga menemukan beberapa kriteria penilaian yang berguna untuk siswa seperti kriteria penilaian dalam akuntansi Laing (2012: 1). Interaksi dari aplikasi computer dapat mengembangkan evaluasi siswa tetang penilaian sikap siswa tentang akuntansi, penilaian akuntansi menggunakan computer juga sangat efektif yang sudah diaplikasikan pada tingkat kurikulum. Hal ini dapat dimaknai, bahwa penilaian dari Laing menonjolkan pada tingkat kurikulum pada evaluasi sikap siswa, sama halnya dengan SMA di Kota Surakarta berpedoman dengan adanya kurikulum KTSP maupun kurikulum 2013. 
Penilaian yang dilakukan oleh guru akuntansi sudah sesuai dengan kriteria penilaian yang sudah ditetapkan, penilaian di SMA Kota Surakarta sangat bagus dari hasil kerja kelompok, portofolio maupun tugas individu sudah mencapai KKM yang telah ditetapkan. Hasil dari penilaian ini berupa hasil ulangan harian, ulangan tengah semester dan akhir semester. Hasil yang diperoleh oleh siswa dalam pembelajaran akuntansi sangat memuaskan, karena di SMA Kota Surakarta sudah menggunakan model pembelajaran yang efektif untuk meningkatkan pengetahuan, pemehaman siswa untuk meraih hasil yang diinginkan. Penilaian yang dilakukan oleh guru akuntansi sudah sesuai dengan kriteria penilaian yang sudah ditetapkan, penilaian di SMA Kota Surakarta sangat bagus dari hasil kerja kelompok, portofolio maupun tugas individu sudah mencapai KKM yang telah ditetapkan. Hasil dari penilaian ini berupa hasil ulangan harian, ulangan tengah semester dan akhir semester. Hasil yang diperoleh oleh siswa dalam pembelajaran akuntansi sangat memuaskan, karena di SMA Kota Surakarta sudah menggunakan model pembelajaran yang efektif untuk meningkatkan pengetahuan, pemahaman siswa untuk meraih hasil yang diinginkan.

\section{KESIMPULAN}

Penilaian Pembelajaran akuntansi di SMA Kota Surakarta untuk aspek afektif ada dua, yaitu penilaian kompetensi sikap spiritual dan penilaian sikap sosial. Penilaian sikap spiritual menggunakan teknik penilaian diri. Penilaian kompetensi sikap sosial menggunakan teknik observasi, jurnal penilaian diri, dan teman sejawat. Penilaian pembelajaran akuntansi untuk aspek kognitif menggunakan tes dan penugasan. Penilaian pembelajaran untuk aspek psikomotorik ada tiga, yaitu penilaian proyek, kinerja dan portofolio.

Pengembangan dilakukan pada instrumen penilaian baik aspek afektif, koknitif, maupun psikomotorik. Pengembangan pada aspek afektif dilakukan instrumen penilaian kompetensi sikap spiritual dan instrumen penilaian kompetensi sikap social dengan teknik observasi. Pengembangan pada aspek kognitif dilakukan pada instrumen penilaian aspek kognitif dan waktu pelaksanaan instrument kognitif. Pengembangan pada aspek psikomotorik dilakukan pada pelaksanaan instrument psikomotorik.

\section{DAFTAR PUSTAKA}

Alleyne, Philmore and Diana Weekes-Marshall. 2011. An Exsploratory Study of Management Accounting Practices In manufacturing Companies in Barbado. of Business International Journal and Social Science 2 (9) (Special Issue-May 2011) pp. 49-58.

Anwar. 2006. "Penggunaan Peta Konsep Melalui Model Pembelajaran Kooperatif Tipe STAD untuk meningkatkan Proses, Hasil Belajar, dan Respons pada Konsep Ekosistem”. Dalam Jurnal Penelitian Kependidikan. Tahun 16 Nomor 1 Desember. Hal. 217-244.

Dallimore, Elice. J. Hertenstein Julie H. dan Platt Majorie B. 2010 Issues In Accounting Education. Class Participation in Accounting Courses: Factors 
That Affect Student Comfort and Learning American Accounting Association DOI:10.2308/ iace.2010.25.4.613. 25 (4) 2010 pp. 613-629.

Djamarah, Syaiful Bahri dan Aswan Zain. 2010. Strategi Belajar Mengajar. Jakarta: Rineka Cipta.

Firdaus, L.N., Gunawan Tabrani, dan Adiwirman. 2007. “Implementasi Pendekatan Contextual-Teaching and Learning (CTL) dalam Pembelajaran dengan Kurikulum Berbasis Kompetensi di Kabupaten Bengkalis Privinsi Riau". Makalah Simposium Nasional 2007. Jakarta 26-27 Juli 2007. Pusat Penelitian Kebijakan dan Inovasi Pendidikan, Badan Penelitian dan Pengembangan, Departemen Pendidikan Nasional Republik Indonesia.

Gregory Kenneth, Laing 2012. Higgher Education Studies Published by Canadian Center of Science and Education I integration of acomputer Application in a first Year Accounting Curriculum: An Evaluation of Student Attitudes, School of Accounting \& Finance, Faculty of Commerce University of Wollongong, Australia, 2 (2); June 2012.

Hamdani. 2011. Strategi Belajar Mengajar. Bandung: Pustaka Setia.

Hamalik, Oemar, 2007, Manajemen Pengembangan Kurikulum, Bandung: PT Remaja Rosda Karya.

Hamruni. 2012. Strategi Pembelajaran, Yogyakarta: Insan Madani.

Jonhson, Elaine B. 2009. Contextual Teaching and Learning, (Terjemahan Ibnu Setiawan, Cetakan VII). Bandung: Mizan Learning Center.

Kirkham, Ross. 2013. An Approach to Improving the Learning Experience for First Year Accounting Currriculum University of the Sunshine Coast, Australia. EJournal of Business Education \& Scholarship of Teaching. 7 (1). 2013, pp.7481.

Kunandar, 2013. Penilaian Autentik, Jakarta: Rajawali Pers.

Lestianto. 2011 Implementasi Model Pembelajaran Kooperatif CIRC berbasis lesson Study untuk meningkatkan asil belajar siswa untuk mata kuliah kewirausa haan.Malang: FE, UM.

Miles, Matthew B. dan A. Michael Huberman. 1992. Analisis Data Kualitatif. Terjemahan Tjetjep Rohendi. Jakarta: Penerbit Universitas Indonesia.

Ninih Rochanah dkk. 2012 Pengembangan Model pembelajaran Berorientasi Konstruktivistik Untuk Meningkatkan Kualitas Pembelajaran Akuntansi di SMA, Jurnal Pendidikan.

O'Leary, Conor dan Stewart Jenny, 2012. J Bus Etthics Accounting and Law Discipline, Griffith Business School.The Interaction of Learning Styles and teaching Methodologiesin Accounting Ethical Introction, Nathan Campus, Griffith University, 170 Kessels Road, Nathan, dan Griffith University, Logan Campus, Logan Australia 113: 225-241. 
Riccio, Edson. I. dan Sakata, Marici, C.G.2005 Teaching Learning Method In Accounting Education-an Empirical Research In the Brazilian Scenario Brazil: University of sa o Paulo. pp.1-14.

Sarjono, Yetty dan Suyatmini. 2011 Model penataan Pedagang Kaki Lima di Surakarta Sebagai Solusi Konstruktif Untuk Pemberdayaan Tingkat Pendidikan Anak-anak PKL, EDUKASI, Jurnal Ilmu pendidikan 10 (2). Hal.18.

Sarjono, Yetty. Dan Suyatmini. 2013. Pengembangan Model Pembelajaran Ekonomi Berbasis Lingkungan Dengan pendekatan pembelajaran Inovatif di SMA Muhammadiyah di Surakarta, Laporan penelitian Pentaspena, Juni 2013.

Sarjono, Yetty dan Suyatmini. 2013 Model Pendidikan Anak-Anak Miskin di Kota Surakarta. Jurnal Manajemen Pendidikan. 8. (2), Juli 2012 Hal. 98-111.

Sugiyono. 2006. Metode Penelitian Kuantitatif, Kualitatif dan R\&D. Bandung: Alfabeta.

Sukiman. 2012 Pengembangan Sistem Evaluasi, Yogyakarta: Insan Madani.

Susilo, Herawati, Husnul Chotimah, Ridwan Joharmawan, Jumiati, Yuyun Dwita Sari, dan Sunarjo. 2009. Lesson Study Berbasis Sekolah. Malang: Bayumedia Publishing.

Sutama. 2012. Metode Penelitian pendidikan (Kuantitatif, Kualitatif, PTK, R \& D) Gumpang -Kartasura: Fairus Media.

Suwarni, Endah, Retno Widiastuti, dan Anna Isrowiyah. 2007. "'Accelereted Learning' sebagai Dasar untuk Meningkatkan Efektivitas dan Efisiensi Proses Balajar Mengajar Akuntasi Pangantar". Makalah Simposium Nasional 2007. Jakarta 26-27 Juli 2007. Pusat Penelitian Kebijakan dan Inovasi Pendidikan, Badan Penelitian dan Pengembangan, Departemen Pendidikan Nasional Republik Indonesia.

Suyatmini. Yetty Sarjono, Titik Asmawati, dan Wafrotur Rohmah 2015. Pengembangan Pengelolaan Pembelajaran akuntansi Kurikulum 2013 Berbasis Lesson Study di SMK Kota Surakarta, Penelitian PUPT RISTEKDIKTI.

Undang- Undang No.20 tahun 2003. Tentang Sistem pendidikan Nasional, Bandung: Cipta Umbara.

Vincent. 2012. International Journal For Lesson And Learning Studies Using Learning Study To Improve The Teaching And Learning of Accounting in a School In Brunei Darusalam 1 (1) 2012. pp. 23-40.

Wafroturrohmah dan Suyatmini, 2008. Penggunaan Metode Problem Based Learning Untuk meningkatkan Kemampuan Belajar Mandiri Mahasiswa Jurusan Pendidikan Akuntansi Pada Mata Kuliah akuntansi Perpajakan, Jurnal Varia Pendidikan 20 (2), Desember 2008 Hal. 154-163. 